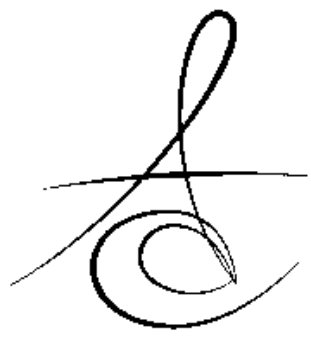

\title{
ÇOCUK DİŞ HEKİMLİĞİNDE TRAVMA HASTALARINDA KULLANILAN SPLİNT TÜRLERİ
}

\author{
SPLINT TYPES USED IN TRAUMA PATIENTS IN PEDIATRIC DENTISTRY \\ REMOVAL
}

Yrd.Doç.Dr. Halenur ALTAN*

\author{
Arş.Gör.Dt.Alem CoşGUN**
}

\begin{abstract}
Makale Kodu/Article code: 2369
Makale Gönderilme tarihi: 28.07.2015

Kabul Tarihi; 03.03.2016
\end{abstract}

öz

Diş travmaları, çocukluk çağında görülen önemli sağlık problemlerinden biridir. Süt veya daimi dişlenme döneminde meydana gelecek bir travma dişlerde pulpa nekrozu, kanal obliterasyonu, mine kalsifikasyon bozuklukları, diş germinin yer değiştirmesi, dişlerin gömülü kalması gibi komplikasyonlarla sonuçlanabilmektedir. Bu nedenle çocukların çene yüz gelişimini etkileyen dental yaralanmalar en iyi ve en doğru şekilde tedavi edilmelidir. Dental travma sonrası etkilenen dişlerde artmış mobiliteyi engellemek amacıyla komşu dişlere splintlenmesi gerekebilmektedir. Bu derlemede diş hekiminin dental yaralanmalarda tercih edeceği splint türleri hakkında güncel bilgiler sunulması amaçlanmıştır.

Anahtar Kelimeler: Çocuk, Splint, Travma

\section{GİRİ̧}

Diş travmaları, çocukluk çağında görülen önemli sağlık problemlerinden biridir ${ }^{1}$. Okul çağındaki çocukların \% 30'unda süt dişlenme de, \% 22'sinde ise daimi dişlenmede travmaya bağlı dental yaralanmalar görülmektedir². Dişsel yaralanmalar genellikle ön dişlerde görülmekte ve özellikle üst kesicileri etkilemektedir $^{3-5}$. Dişsel yaralanmalarda kesiciler \% 97 oranında etkilenmektedir. Kesicilerin travma görme oranları \% 34 üst santral, \% 6 üst lateral, \% 6 alt santral, \% 3 alt lateral şeklindedir ${ }^{6}$.

Süt dişlerine gelen travma sonucunda, dişlerde pulpa nekrozu ve kanal obliterasyonu görülebilmektedir. Ayrıca, süt dişinin altındaki daimi diş germi zarar görebilmektedir. Bunun sonucunda daimi dişte mine

\section{ABSTRACT}

Dental trauma is one of the major health problems in childhood. A trauma occured in deciduous or permanent dentition may result in complications such as pulp necrosis, root canal obliterations, enamel decalcification, displacement of tooth germ, embedded tooth. Therefore, dental injuries affecting the maxillofacial development of children should be treated in the best and most accurate way. Splinting of adjacent teeth may need to be increased in order to prevent the mobility of the affected teeth after dental trauma. This review has been presented to give contemporary literature about the types of splints will choose by dentist.

Key Words: Child, splint, trauma kalsifikasyon bozuklukları, diş germinin yer değiştirmesi, dişlerin gömülü kalması gibi komplikasyonlar meydana gelebilmektedir. Kök gelişimi devam eden daimi dişlerde travma sonucu kök gelişimi durabilir, kök boyu kısa kalabilir ve kökte dilaserasyon görülebilir. Travma daimi dişlenme döneminde olursa alveol kırıkları, kök kırıkları ve maloklüzyon gibi komplikasyonlar meydana gelebilmektedir. Bu nedenle çocukların çene yüz gelişimini etkileyen dental yaralanmalar en iyi ve en doğru şekilde tedavi edilmelidir.

Süt ve daimi dişlenmeyi etkileyen travmalara bağlı yaralanmaları içeren çalışmalar incelendiğinde düşme ve bisiklet kazaları dental travma etiyolojisinde ilk sıralarda yer almaktadır ${ }^{1,4,7-10}$. Dental travma etiyolojisinde yaş, cinsiyet ve oklüzyon türü rol oynamaktadır. 1-3 yaş arası çocuklarda yürümenin yeni öğrenildiği ve aynı zamanda kas kontrolü ve karar yetisi

\footnotetext{
*Gaziosmanpaşa Üniversitesi, Diş Hekimliği Fakültesi, Çocuk Diş Hekimliği AD.

** Mustafa Kemal Üniversitesi, Diş Hekimliği Fakültesi, Çocuk Diş Hekimliği AD.
}

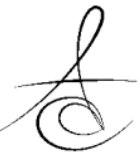


tamamlanmadığı için travma riski artmaktadır. 7-10 yaş arası okul çağı döneminde ise sosyalleşme, çocuğun kendi vücudunu ve yeteneklerini tanıması ve bireysel sportif aktivitelerindeki artış ile travma görülme oranı tekrar artmaktadır ${ }^{7,11,12}$. Genellikle erkek çocukların kız çocuklara oranla travmaya daha yatkın olduğu gözlenmekle birlikte ${ }^{1,3,4,13-15}$, bazı araştırmacılar kız çocukların da en az erkek çocuklar kadar risk taşıdığı bildirmiştir ${ }^{16,17}$. Sınıf II Bölüm I iskeletsel kapanış ilişkisine sahip, ağız solunumu yapan ve şiddetli üst solunum yolu rahatsızlıkları olan çocuklar travma açısından risk taşımaktadır ${ }^{1,3}$. Ayrıca overjeti fazla olan çocukların travmaya yatkın olduğu gözlenmiştir ${ }^{18}$. 3-6 $\mathrm{mm}$ arası overjete sahip çocuklar 0-3 $\mathrm{mm}$ arası overjete sahip çocuklara göre 2 kat, $6 \mathrm{~mm}$ 'den fazla overjeti olanlar ise 3 kat daha fazla risk taşımaktadırlar ${ }^{19}$.

Daimi dişlerde kök kırığı, alveolar kemik kırığı, sublüksasyon, ekstrüzyon, lateral lüksasyon ve intrüzyon vakalarında splint uygulanması önerilmektedir. ${ }^{20}$

Travma süt dişlerini içerdiği zaman, ilgi hem etkilenen süt dişlerine hem de altta gelişen sürekli diş germlerine yönlendirilmelidir. Her girişim gelişen diş tomurcuklarını koruma amacı taşımalı ve tedavi planları buna göre hazırlanmalıdır ${ }^{21}$.

Süt dişlerinde splint uygulaması, süt dişindeki malpozisyonun derecesi, çocuğun kooperayonu, diş yaşı ve süt dişinin düşme zamanının yakın olup olmaması dikkate alınarak alveol kırığı, lateral lüksasyon ve ekstrüzyon vakalarında yapılabilmektedir ${ }^{22}$. Bazı araştırmacılara göre süt dişlenme döneminde sadece alveol kırığı vakalarında splint uygulaması önerilmektedir ${ }^{23}$.

Günümüzde kullanılan travma splintlerinin sahip olması istenen özellikler, klinikte bulunan geleneksel materyallerle kolaylıkla hazırlanabilmesi, uygulanmasının kolay olması, dental sert dokulara zarar vermeden uzaklaştırılabilmesi ve ucuz olmasıdır. Splintler dişlere ve çevre dokulara zarar vermemeli, oklüzyonu, ağız hijyeni ve endodontik tedaviyi engellememelidir. Orijinal anatomik diş pozisyonunun restore edilmesine olanak sağlamalı ve travmanın tipine göre immobilizasyon periyodu boyunca uygun fiksasyonu sağlamalı ve fleksibl olmalıdır ${ }^{24-27}$.

Dental travma sonrası etkilenen dişlerin, akut periodontal lezyonlara bağlı artmış mobilitesini engellemek amacıyla komşu dişlere splintlenmesi gerekmektedir $^{28}$. Adeziv diş hekimliğinden önce kök kırıkları altın, akrilik cap splint ya da arch barlar ile rijit olarak splintlenmiştir $^{29}$. İlerleyen zamanlarda cap splint ve ortodontik uygulamalar (simante edilen bantlar ile) ile immobilizasyon terk edilmiştir, bunların yerini çeşitli modifikasyonlar yapılarak adeziv sistemler almıştır. Kevlar splint (Du Pont, Wilmington, DE, USA) ile kök kırığı olan kesicilerin koronal parçasına bağlayıcı ajan uygulanarak dişlere fiberglass tutturulup dişlerin sabitlenmesi sağlamıştır. Kevlar splintlerin daha az travmatik olduğu ve daha kısa sürede uygulandığı düşünülmüştür ${ }^{30}$.

Günümüze kadar çeşitli splintler kullanılmıştır. Güncel olarak kullanılan splintler; ortodontik telkompozit splint, misina-kompozit splint, titanyum halka splint, titanyum travma splint, fibercam(Ribbond), braket splint ve akrilik splinttir. (Tablo 1, Resim 1)

\section{Tablo 1.Splintlerin sınıflandırılması}

\begin{tabular}{|c|c|}
\hline ESNEK SPLİNTLER & RİJ̇T SPLİNTLER \\
\hline $\begin{array}{ll}- & \text { Misina-kompozit splint } \\
\text { - } & \text { Fibercam splint } \\
\text { - } & \text { Titanyum travma splint } \\
\text { - } & \text { Paslanmaz çelik tel-kompozit } \\
\text { splint }(0,3 \mathrm{~mm} \leq \text { tel } \\
\text { kalınlığı<0,5mm) } \\
\text { Nikel titanyum tel-kompozit } \\
\text { splint } \\
(0,3 \mathrm{~mm} \leq \text { tel } \\
\text { kalınlıăı } \leq 0,5 \mathrm{~mm})\end{array}$ & $\begin{array}{ll}\text { - } & \text { Titanyum halka splint } \\
\text { - } & \text { Akrilik splint } \\
\text { - } & \text { Kompozit splint } \\
\text { - } & \text { Cap splint } \\
\text { - } & \text { Simante bantlar ile yapılan } \\
& \text { ortodontik uygulamalar } \\
\text { - } & \text { Paslanmaz çelik tel- } \\
& \text { kompozit splint } \\
& (0,5 \mathrm{~mm} \leq \text { tel kalınlığı) }\end{array}$ \\
\hline
\end{tabular}

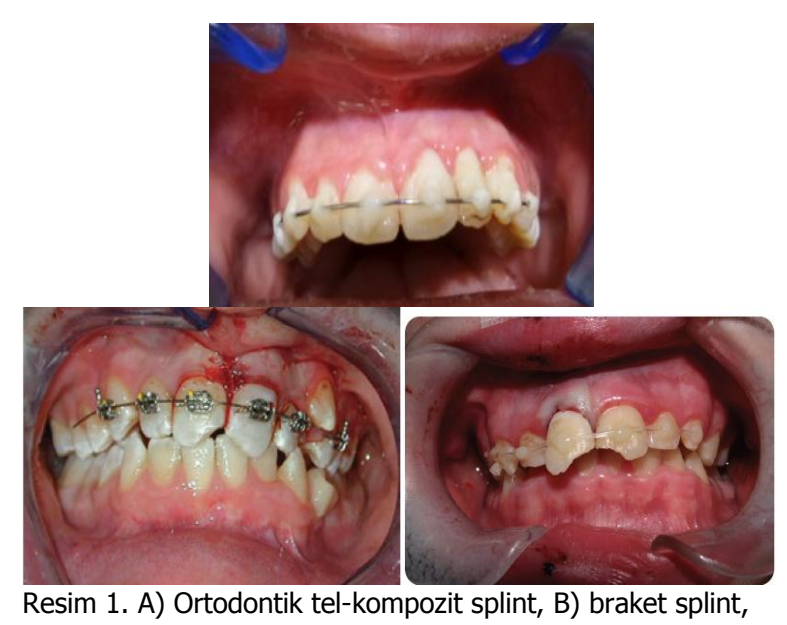

C) misina-kompozit splint

Ortodontik tel-kompozit splintlerde öncelikle ortodontik tel diş arkına uyumlanmaktadır. Etkilenen diş ve komşu dişlerin splint uygulanacak yüzeyine asitle pürüzlendirme ve bağlayıı ajan uygulaması yapılmaktadır. Son olarak ortodontik tel dişlere kompozit yardımıyla tutturulmaktadır ${ }^{31}$. Ortodontik tel-kompozit splintlerin avantajı kullanılan materyallerin ucuz ve kliniklerde rutin olarak bulunabilen materyaller olmalarıdır ${ }^{32}$. 
Misina-kompozit splint dişlerin splint uygulanacak yüzüne asit ile pürüzlendirilip, bağlayıcı ajan uygulanmasından sonra kompozit kullanılarak dişlere uygulanır. Ortodontik tel-kompozit splintlerden farkı diş arkına uyumlama gereksiniminin olmamasıdır. Misina- kompozit splintin diş şekline uyum sağlaması, tel kullanılarak yapılan splint çeşitlerine göre estetik olması, ucuz olması, kolay uygulanması ve uzaklaştırıması gibi özellikleri en önemli avantajlarındandır ${ }^{33}$.

Titanyum halka splintlerle yapılan tedavilerde splint diş arkına uyumlandıktan sonra, ortodontik telkompozit splintlerde olduğu gibi dişlerin uygulanacak yüzüne asit ve bağlayıcı ajan uygulanmaktadır. Splintteki prefabrike boşluklara kompozit yerleştirilerek splint dişler üzerine sabitlenmektedir ${ }^{32}$. Titanyum travma splintlerin uygulama metodu ortodontik tel-kompozit splint ile aynıdır ${ }^{26}$. Titanyum travma splint kısa süreli uygulama ve uzaklaştırma süresine sahip olduğundan, yaşı küçük hastalarda daha rahat kullanılabilmektedir ${ }^{34}$. Fibercam(Ribbond) splintlerin uygulama metodu misina-kompozit splint ile aynıdır.

Çapraşıkığı bulunan travma hastalarında ağız içerisinde kompozit-tel kombinasyonu splint yapımı zor olduğundan fiber ile güçlendirilmiş lingual retainer bir alternatif olabilir ${ }^{35}$.

Braketlerle splintlemede dişlerin ön yüzüne asit ve bağlayıcı ajan uygulaması sonrası kompozit yardımıyla braketler etkilenen diş ve komşu diş yüzeylerine yerleştirilmektedir. Sonrasında bu braketleri saran bir ligatür teli yardımıyla dişler sabitlenmektedir $^{32}$. Bir diğer splint tipi akrilik splintlerdir ve genellikle süt dişi lüksasyonlarında ve karma dişlenme döneminde etkilenen dişin distalinin dişsiz sonlandığı vakalarda tercih edilebilir. Alçı model elde edebilmek için hastadan ölçü alınması gerekmektedir. Bu ölçü alma safhası yanak, dudak ve mukozadaki yaralanmalar, trismus ve ağrı gibi durumlarda oldukça zor hatta imkansız olabilmektedir. Ayrıca aşııı derecede lüksasyon gösteren dişlerde ölçü alma safhasında dişin soketten çıkma intimali de vardır. Uygulanması hassasiyet gerektiren bir yöntemdir ${ }^{36}$.

Kompozit splintlerde etkilenen dişe ve bu dişe komşu olan dişlerin yüzeylerine asitle pürüzlendirmeyi takiben bağlayıı ajan uygulaması yapılmaktadır. Daha sonra diş yüzeyleri birbirlerine kompozit rezinler yardımıyla bağlanmaktadır ${ }^{37}$. Sadece kompozit rezinlerle yapılan splintleme tipinde dişin aproksimal kısımlarında kompozit bulunduğundan splintin sökülmesi dişte ek bir travmaya neden olmaktadır. Bu nedenle ortodontik tel- kompozit splintler tercih edilmektedir ${ }^{38}$.

Dental travmayı takiben splintleme ile dişlere etki eden kuvvetlerin yönünün modifiye edilmesi amaçlanmaktadır. Lateral kuvvetler, kemik bütünlüğünün yeniden sağlanması ve periodontal ligament fibrillerinin yeniden düzenlenmesiyle daha çabuk iyileşme sağlayan ve diş destek dokuları için daha az zararlı olan vertikal kuvvetlere dönüştürülmektedir ${ }^{39}$. Yapılan tedavinin başarıı olması için iyileşmesi istenen dokulara hafif derecede kuvvet gelmesi ve travmatize sokette bulunan dişlerde kontrollü hareket (yaklaşık 50 $\mu \mathrm{m})$ olması gerekmektedir ${ }^{40}$. Yani travma geçiren dişin fizyolojik hareketlere izin vermesi gerekmektedir ${ }^{30}$. Rijit splintlemenin periodontal ligamentte aşıı bir sıkışma meydana getirerek periodontal neoanjiyogeziste bozulmaya sebep olduğu, mekanik uyaran ile revaskülarizasyona yardımcı olan orta-hafif derecede diş hareketine izin veren splintlerin ise, ankiloz oluşturmadığı ve kök gelişiminde canlı kalması gereken hertwing epitel kınını koruduğu bildirilmiştir ${ }^{41,42}$. Fizyolojik hareketler periodontal ligamentteki kan akımını ve venöz dönüşü sağlayarak revaskülarizasyonu teşvik eder ${ }^{43}$. Tam hareketsizlik, mekanik uyaran kaybına neden olduğu için fibroblastlar üzerinde yıkııı etki yapar, kollajen kitlesi azalır ve iyileşmeyi engeller ${ }^{44}$. Periodontal liflerin iyileşmesini hızlandırmak ve travmaya maruz kalmış dişlerin fizyolojik hareketinin sağlanması için splintlerin pasif ve esnek olması gerekmektedir ${ }^{45}$. Yapılan çalışmalar yüksek esnekliğe sahip olan splintlerle stabilize edilen dişlerde kök rezorbsiyonunun daha az oranda görüldüğünü ve rijid splintle splintlenen dişlere oranla periodontal liflerde reorganizasyonun daha iyi olduğunu göstermiştir ${ }^{46}$

\section{Splint çeşitleri üzerine yapılan in vivo ve in vitro çalışmalar}

Kwan ve ark. ${ }^{47}$ yaptıkları çalışmada insan kadavra modeli kullanarak sekiz farklı splint tipinin çekilen ve reimplante edilen dişlerin mobilitesi üzerindeki etkisini karşılaşıımışlardır. Karşılaştırılan splint tipleri paslanmaz çelik splint $(0.3 \mathrm{~mm}, 0.4 \mathrm{~mm}, 0.5 \mathrm{~mm}$ kalınlıklarında), nikel titanyum splint $(0.3 \mathrm{~mm}, 0.4 \mathrm{~mm}, 0.5$ $\mathrm{mm}$ kalınlıklarında), misina-kompozit splint ve kompozit splintttir. Yapılan çalışmanın sonucuna göre farklı kalınlıktaki nikel titanyum-kompozit splintlerinde benzer mobilite görülmüştür. Paslanmaz çelik-kompozit splintlerde ise kalınlık arttıkça mobilitede azalma gö-

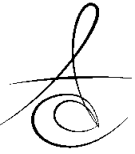


rülmüştür. Kompozit splintin mobiliteye etkisi misinakompozit splint ve diğer tel-kompozit splintlere göre anlamlı derecede fazladır. Misina-kompozit splint ve diğer tel-kompozit splintler arasında anlamlı derecede fark bulunmamıştır. Sonuç olarak esnek splint olarak misina-kompozit splint ya da ince tel-kompozit splintin kullanılabileceği bildirilmişmiştir. Kompozit splintin ve $0.4 \mathrm{~mm}$ den kalın tel-kompozit splintin fizyolojik mobiliteye izin vermediğini bildirilmiştir.

Berthold ve ark. ${ }^{32}$ yaptıkları çalışmada yuvarlak, kare ve dikdörtgen kesitli 3 değişik tip ortodontik tel ile yapılan splintleri karşılaştırmışlardır. Sonuç alarak tam yuvarlak veya kare tel ile yapılan tel-kompozit splintlerin ve titanyum travma splintlerin avülsiyon vakalarında daha başarılı olduğu bildirilmiştir. Araştırmacılar dikdörtgen tel ile yapılan tel- kompozit splintlerin ve titanyum halka splintlerin rijit splintleme gereken alveol kemik kırıklarında daha etkili olduğunu ortaya koymuşlardır.

Cengiz ve ark. ${ }^{40}$ ortodontik tel-kompozit splint ve titanyum travma splintlerin dişlere iletilen stres değerleri açısından karşılaştırmışlardır. Araştırmacılar, ortodontik tellerle yapılan splintlerin dişlere iletilen stres değerlerinin, titanyum travma splintlerinin uygulandığı stres değerlerinden anlamlı derecede daha düşük olduğunu ortaya koymuşlardır.

Andreasen ve ark. ${ }^{30}$ kök kırığı olan dişlerde beş farklı splint tekniğinin fragmanlar arasındaki sert doku iyileşmesi, pulpa iyileşmesi ve pulpa nekrozu üzerine etkilerini karşılaştırmışlardır. Bu splint teknikleri arch bar-ortodontik bant, cap splint, kompozit splint, kompozit-arch bar splint ve fibercam(Kevlar) splinttir. Sonuç olarak sert doku parçaları arasındaki en iyi iyileşme arch bar-ortodontik bant ve fibercam(Kevlar) splintlerde görülmüştür. Periodontal doku iyileşmesinde splint tipleri arasında anlamlı derecede bir fark bulunmamıştır. Diğer splint tipleriyle karşılaştırıldığında ise fibercam(Kevlar) splint pulpa nekrozunda anlamlı bir düşüş göstermiştir. Cap splintin ise pulpa nekrozunu arttırdığı bildirilmiştir. Bunun sebebinin ölçü alırken ve simantasyon sırasında alınan ek travmalarla ilişkili olduğu belirtilmiştir. Ayrıca mutlak rijidite, iyileşme ve oral hijyen üzerine zararlı etki göstermiştir. Bu çalışmada fibercam(Kevlar) splintin periodontal doku iyileşmesinde optimal derece başarı göstermiştir. Bu splintin in vitro çalışmada kısmen elastik olduğu ve uygulama esnasında dişe zarar vermediği belirtilmiştir.
Flippi ve ark. ${ }^{34}$ ortodontik tel-kompozit splint, braket splint, kompozit splint ve titanyum travma splinti karşılaştırmışlardır. Titanyum travma splintin ve ortodontik tel-kompozit splintin diş mobilitesine normal dişlerin fizyolojik mobilitesine en yakın seviyede izin verdiği, kompozit splintin ise fizyolojik mobiliteden daha az bir mobiliteye izin verdiği bildirilmiştir. Dudakları en fazla irrite eden, en fazla yer kaplayan ve konuşmaya en fazla engel olan splint çeşidinin braket splint olduğu, diş etini en fazla irrite eden, en fazla plak birikimine neden olan ve diş firçalamaya en fazla engel olan splintin ise kompozit splint olduğu belirtilmiştir. Braket splint ve ortodontik tel-kompozit splintin aynı derecede plak akümülasyonuna sebep olduğu belirtilmiştir. Titanyum travma splint ve ortodontik telkompozit splint yumuşak dokuları daha az irrite etmesi, hastalar tarafından tolere edilebilmesi ve diş mobilitesine normal dişlerin fizyolojik mobilitesine en yakın seviyede izin vermesi nedeniyle kullanılmaları önerilmiştir. ${ }^{23}$

Mazzoleni ve ark. ${ }^{28}$ fibercam(Kevlar) splint, rezin splint, tel-kompozit splint, braket splint ve titanyum travma splint fleksibilitelerini in-vitro olarak karşılaştırmışlardır. Fleksibilitesi en yüksek olan splint titanyum travma splint ve fibercam(Kevlar) splint iken; rezin splint ise en rijid splinttir ve periodontal ligamentin iyileşmesi için gerekli olan diş mobilitesine izin vermemektedir. Braket splint ve ortodontik telkompozit splintler fleksibilite özelliği göstermektedir, buna rağmen optimal iyileşme için gerekli fizyolojik mobiliteyi sağlayamamaktadır.

\section{SONUÇ}

Günümüzde travma sonucu dental yaralanma meydana gelen dişlerin, arkta doğru konumlanması ve fizyolojik fonksiyonlarını yerine getirebilmesi amacıyla elastik splint kullanılması önerilmektedir

\section{KAYNAKLAR}

1. Cameron A, Widmer A, Gregory P, Abbott P. Handbook of Pediatric Dentistry. 2 ed. London; Mosby: 1998. p. 95-113.

2. Rao A. Principles and Practice of Pedodontics. 1 ed. New Delhi; Jaypee: 2008. p. 304.

3. Cho SY. Dental luxation and avulsion injuries in Hong Kong primary school children. Hong Kong Med J 2015;21:339-44. 
4. Gojanur S, Yeluri R, Munshi AK. Prevalence and Etiology of Traumatic Injuries to the Anterior Teeth among 5 to 8 Years Old School Children in Mathura City, India: An Epidemiological Study. Int J Clin Pediatr Dent 2015;8:172-5.

5. Berti GO, Hesse D, Bonifacio CC, Raggio DP, Bonecker MJ. Epidemiological study of traumatic dental injuries in 5- to 6-year-old Brazilian children. Braz Oral Res 2015;29:1-6.

6. Skaare $A B$, Jacobsen I. Etiological factors related to dental injuries in Norwegians aged 7-18 years. Dent Traumatol 2003;19:304-8.

7. Andreasen J, Andreasen F, Bakland L, Flores M. Traumatic dental injuries: A manual. 2. ed. United Kingdom; Willey-Blackwell: 2003. p. 8-71.

8. Kargul B, Caglar E, Tanboga I. Dental trauma in Turkish children, Istanbul. Dent Traumatol 2003;19:72-5.

9. Sandalli N, Cildir S, Guler N. Clinical investigation of traumatic injuries in Yeditepe University, Turkey during the last 3 years. Dent Traumatol 2005;21:188-94.

10. Onetto JE, Flores MT, Garbarino ML. Dental trauma in children and adolescents in Valparaiso, Chile. Endod Dent Traumatol 1994;10:223-7.

11. Caglar E, Sandalli N. Dental and orofacial trauma in pony and horseback riding children. Dent Traumatol 2006;22:287-90.

12. Caglar E, Ferreira LP, Kargul B. Dental trauma management knowledge among a group of teachers in two south European cities. Dent Traumatol 2005;21:258-62.

13. Cardoso M, de Carvalho Rocha MJ. Traumatized primary teeth in children assisted at the Federal University of Santa Catarina, Brazil. Dent Traumatol 2002;18:129-33.

14. Segura JJ, Poyato M. Tooth crown fractures in 3year-old Andalusian children. J Dent Child (Chic) 2003;70:55-7.

15. Wood EB, Freer TJ. A survey of dental and oral trauma in south-east Queensland during 1998. Aust Dent J 2002;47:142-6.

16. Kramer PF, Feldens EG, Bruch CM, Ferreira SH, Feldens CA. Clarifying the effect of behavioral and clinical factors on traumatic dental injuries in childhood: a hierarchical approach. Dent Traumatol 2015;31:177-83.
17. Glendor U, Halling A, Andersson L, Eilert-Petersson E. Incidence of traumatic tooth injuries in children and adolescents in the county of Vastmanland, Sweden. Swed Dent J 1996;20:15-28.

18. Correa-Faria P, Paiva SM, Pordeus IA, RamosJorge ML. Influence of clinical and socioeconomic indicators on dental trauma in preschool children. Braz Oral Res 2015;29:1-7.

19. Hall RK. Pediatric Orofacial Medicine and Pathology. 1 ed. London; Chapman \& Hall Medical: 1994. p. $90-8$.

20. Diangelis AJ, Andreasen JO, Ebeleseder KA, et al. International Association of Dental Traumatology guidelines for the management of traumatic dental injuries: 1. Fractures and luxations of permanent teeth. Dent Traumatol 2012;28:2-12.

21. Tsukiboshi M. Travma Olgularınnda Tedavi Planlaması. 1 ed. İstanbul; Quintessence: 2007. p. 105.

22. Flores MT. Traumatic injuries in the primary dentition. Dent Traumatol 2002;18:287-98.

23. Flores MT, Malmgren $B$, Andersson $L$, et al. Guidelines for the management of traumatic dental injuries. III. Primary teeth. Dent Traumatol 2007;23:196-202.

24. Guideline on management of acute dental trauma. Pediatr Dent 2008;30:175-83.

25. Finucane D, Kinirons MJ. External inflammatory and replacement resorption of luxated, and avulsed replanted permanent incisors: a review and case presentation. Dent Traumatol 2003;19:170-4.

26. von Arx T, Filippi A, Buser D. Splinting of traumatized teeth with a new device: TTS (Titanium Trauma Splint). Dent Traumatol 2001;17:180-4.

27. Garla BK, Deshmukh S, Murthy PS, Satish G. Modified Esthetic Splint Design for Management of Multiple Traumatic Injuries in Children: A Case Report. J Int Oral Health 2015;7:124-6.

28. Mazzoleni S, Meschia G, Cortesi R, et al. In vitro comparison of the flexibility of different splint systems used in dental traumatology. Dent Traumatol 2010;26:30-6.

29. Andreasen JO. Buonocore memorial lecture. Adhesive dentistry applied to the treatment of traumatic dental injuries. Oper Dent 2001;26:32835.

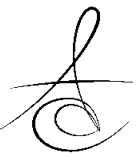


30. Andreasen JO, Andreasen FM, Mejare I, Cvek M. Healing of 400 intra-alveolar root fractures. 2. Effect of treatment factors such as treatment delay, repositioning, splinting type and period and antibiotics. Dent Traumatol 2004;20:203-11.

31. von Arx T, Filippi A, Lussi A. Comparison of a new dental trauma splint device (TTS) with three commonly used splinting techniques. Dent Traumatol 2001;17:266-74.

32. Berthold C, Thaler A, Petschelt A. Rigidity of commonly used dental trauma splints. Dent Traumatol 2009;25:248-55.

33. Berude JA, Hicks ML, Sauber JJ, Li SH. Resorption after physiological and rigid splinting of replanted permanent incisors in monkeys. J Endod 1988; 14:592-600.

34. Filippi A, von Arx T, Lussi A. Comfort and discomfort of dental trauma splints - a comparison of a new device (TTS) with three commonly used splinting techniques. Dent Traumatol 2002;18:27580.

35. Oz A, Dede DO, Dincyurek C, Ozer M, Telcioglu T. Üst Keser Dişlerde Meydana Gelen Travma Sonrası Multidisipliner Tedavi Yaklaşımı: Bir Olgu Sunumu. Cumhuriyet Dental Journal 2010;13.

36. Ayhan E. Ön Bölge Dental Travmalar ve Tedavilerinde Kullanılan Fiksasyon Yöntemlerinin Klinik Araştırması.Ege Üniversitesi Sağlık Bilimleri Enstitüsü Doktora Tezi.; 1999.

37. Neaverth EJ, Georig AC. Technique and rationale for splinting. J Am Dent Assoc 1980;100:56-63.

38. Andreasen J. Traumatic Injuries of the teeth. 2 ed. Philadelphia; WB Saunders: 1981. p. 119-50.

39. Ferencz JL. Splinting. Dent Clin North Am 1987;31:383-93.

40. Burcak Cengiz S, Stephan Atac A, Cehreli ZC. Biomechanical effects of splint types on traumatized tooth: a photoelastic stress analysis. Dent Traumatol 2006;22:133-8.

41. Kelly JR. Perspectives on strength. Dent Mater 1995;11:103-10.

42. Bauss O, Schwestka-Polly R, Schilke R, Kiliaridis S. Effect of different splinting methods and fixation periods on root development of autotransplanted immature third molars. J Oral Maxillofac Surg 2005;63:304-10.
43. Yasuda T, Kinoshita M, Abe M, Shibayama Y. Unfavorable effect of knee immobilization on Achilles tendon healing in rabbits. Acta Orthop Scand 2000;71:69-73.

44. Amiel D, Woo SL, Harwood FL, Akeson WH. The effect of immobilization on collagen turnover in connective tissue: a biochemical-biomechanical correlation. Acta Orthop Scand 1982;53:325-32.

45. Andreasen JO, Andreasen FM, Mejare I, Cvek M. Healing of 400 intra-alveolar root fractures. 2. Effect of treatment factors such as treatment delay, repositioning, splinting type and period and antibiotics antibiotics. Dent Traumatol 2004; 20 : 203-11.

46. Andreasen JO, Andreasen FM, Andersson L. Textbook and Color Atlas of Traumatic Injuries to the Teeth. 4 ed. Oxford; Wiley: 2013. p. 444-88.

47. Kwan SC, Johnson JD, Cohenca N. The effect of splint material and thickness on tooth mobility after extraction and replantation using a human cadaveric model. Dent Traumatol 2012;28:277-81

\author{
Yazışma Adresi \\ Arş.Gör.Dt.Alem Coşgun \\ Mustafa Kemal Üniversitesi \\ Diş Hekimliği Fakültesi \\ Çocuk Diş Hekimliği AD \\ Hatay, Türkiye \\ e-mail: alemcosgun@hotmail.com
}

